Zwinkels, M., Verschuren, O., Janssen, T.W.J., Ketelaar, M., Takken, T. Exercise training programs to improve hand rim wheelchair propulsion capacity: a systematic review. Clinical

\begin{tabular}{|l|l|}
\hline $\begin{array}{l}\text { Postprint } \\
\text { Version }\end{array}$ & 1.0 \\
\hline Journal website & http://cre.sagepub.com/content/28/9/847.long \\
\hline Pubmed link & $\underline{\text { http://www.ncbi.nlm.nih.gov/pubmed/24615862 }}$ \\
\hline DOI & $10.1177 / 0269215514525181$ \\
\hline
\end{tabular}

This is a NIVEL certified Post Print, more info at http://www.nivel.eu

\title{
Exercise training programs to improve hand rim wheelchair propulsion capacity: a systematic review
}

MAREMKA ZWINKELS ${ }^{1-3}$, OLAF VERSCHUREN ${ }^{1-4}$, THOMAS WJ JANSSEN ${ }^{5,6}$, MARJOLIJN KETELAAR $^{1-4}$ AND TIM TAKKEN ${ }^{3,7}$ ON BEHALF OF THE SPORT-2-STAY-FIT STUDY GROUP

1 Brain Center Rudolf Magnus and Center of Excellence for Rehabilitation Medicine, University Medical Center Utrecht, The Netherlands 2De Hoogstraat Rehabilitation, Utrecht, The Netherlands 3 Shared Utrecht Pediatric Exercise Research (SUPER) Lab, Utrecht, The Netherlands

4 Network for Childhood Disability Research, The Netherlands

5 Rehabilitation Research Centre Reade, Amsterdam, The Netherlands

6 Research Institute MOVE, Faculty of Human Movement Sciences, VU University Amsterdam, The Netherlands 7 Child Development \& Exercise Center, Wilhelmina Children's Hospital, UMC Utrecht, Utrecht, The Netherlands

\begin{abstract}
Objective: An adequate wheelchair propulsion capacity is required to perform daily life activities. Exercise training may be effective to gain or improve wheelchair propulsion capacity. This review investigates whether different types of exercise training programs are effective in improving wheelchair propulsion capacity.

Data sources: PubMed and EMBASE databases were searched from their respective inceptions in October 2013.

Review methods: Exercise training studies with at least one outcome measure regarding wheelchair propulsion capacity were included. In this study wheelchair propulsion capacity includes four parameters to reflect functional wheelchair propulsion: cardio-respiratory fitness (aerobic capacity), anaerobic capacity, muscular fitness and mechanical efficiency. Articles were not selected on diagnosis, training type or mode. Studies were divided into four training types: interval, endurance, strength, and mixed training.

Methodological quality was rated with the PEDro scale, and the level of evidence was determined.

Results: The 21 included studies represented 249 individuals with spinal-cord injury (50\%), various diagnoses like spina bifida (4\%), cerebral palsy $(2 \%)$,
\end{abstract}


Zwinkels, M., Verschuren, O., Janssen, T.W.J., Ketelaar, M., Takken, T. Exercise training programs to improve hand rim wheelchair propulsion capacity: a systematic review. Clinical Rehabilitation: 2014, 28(9), 847-861

traumatic injury, (3\%) and able-bodied participants (38\%). All interval training studies found a significant improvement of $18-64 \%$ in wheelchair propulsion capacity. Three out of five endurance training studies reported significant effectiveness. Methodological quality was generally poor and there were only two randomised controlled trials.

Conclusion: Exercise training programs seem to be effective in improving wheelchair propulsion capacity.

However, there is remarkably little research, particularly for individuals who do not have spinal-cord injury.

\section{INTRODUCTION}

Increasing physical activity level is associated with a lower risk of developing cardiovascular diseases. ${ }^{1}$ Compared to able-bodied individuals, manual wheelchair users have reduced physical activity ${ }^{2,3}$ and physical fitness levels. ${ }^{4}$ This has a major impact on their daily life activities, social participation, and overall quality of life. ${ }^{5-7}$ The intensity of wheelchair propulsion in daily life may not put sufficient stress on the cardiovascular system to induce positive health effects. ${ }^{8}$ Hence, breaking through the vicious cycle of deconditioning in manual wheelchair users may require exercise training, i.e. a type of physical activity consisting of standardized, planned, structured, and repetitive bodily movement intended to improve or maintain one or more components of physical fitness. ${ }^{9}$ Improving physical fitness may also result in reduced relative effort in daily activities. Since manual wheelchair users' primary means of mobility is through hand rim wheelchair propulsion, exercise training should aim to improve their physical fitness levels in such a way that hand rim wheelchair propulsion has the greatest impact in daily life. The capacity for hand rim wheelchair propulsion is referred to as wheelchair propulsion capacity. Since both long and short bouts of activity are important in daily life, ${ }^{10}$ wheelchair propulsion capacity is divided into endurance and sprint capacity.

Optimized wheelchair propulsion capacity requires cardio-respiratory fitness (aerobic capacity), anaerobic capacity and muscular fitness (Figure 1). ${ }^{11}$ In addition, these physiological parameters need to be translated into functional wheelchair propulsion. Besides physical fitness, mechanical efficiency is also important for wheelchair propulsion capacity. Power output during hand rim wheelchair propulsion is regarded as the outcome measure most closely related to wheelchair propulsion capacity. ${ }^{12}$ Other 'integrated' outcome measures for wheelchair propulsion capacity are the results of wheelchair propulsion tests in practical situations field tests.

Valent et al $(2007)^{13}$ reviewed studies on the effect of upper-body exercise and reported that no conclusions could be drawn because of the overall low quality of studies. They focused on persons with spinal-cord injury only. Training of wheelchair propulsion capacity might be beneficial for more diagnostic groups, and knowledge on training effects in able-bodied subjects might provide more insight in the potential effects for persons with disabilities.

In addition, exercise training should have its effect on daily life wheelchair propulsion. The focus of the present review will therefore be on integrated wheelchair propulsion outcome measures instead of specifically types of training or bodily related outcome measures. Moreover, several years have passed since the last review. Therefore, the present review aims to systematically review the literature on 
Zwinkels, M., Verschuren, O., Janssen, T.W.J., Ketelaar, M., Takken, T. Exercise training programs to improve hand rim wheelchair propulsion capacity: a systematic review. Clinical Rehabilitation: 2014, 28(9), 847-861

the effectiveness of training programs in improving hand rim wheelchair propulsion capacity, including various groups and all types of training programs.

\section{METHODS}

The PubMed and EMBASE databases were searched from their respective inceptions until October 2013. Search terms included subject headings and text words based on the concepts of 'exercise' or 'physical' and 'wheelchair' with the following constraints: english language and human.

Inclusion criteria were: standardized and clearly described exercise training, and at least one outcome measure regarding endurance or sprint wheelchair propulsion capacity. Articles were not selected on type or mode of exercise; training could be either with or without wheelchair. Titles and abstracts of the electronic searches were scrutinized by one author (MZ). References of included studies were screened to find articles that might have been missed. Included articles were read in full by two independent reviewers (MZ and OV), both trained in exercise physiology and rehabilitation.

They recorded details of the study design, participants, intervention program, training type, outcome measures, results, and conclusions. Where key information was not reported, efforts were made to contact the authors to obtain further details.

Exercise training programs were divided into five predetermined categories: aerobic exercise training, subdivided into interval and endurance training; anaerobic exercise training; strength training; and mixed training. Aerobic exercise training was defined as training aimed at improving the function of the cardio-respiratory system. ${ }^{14}$ There are roughly two ways of training the cardio-respiratory system: interval and endurance training. Interval training involves bursts of high-intensity work interspersed with periods of low-intensity exercise. ${ }^{15}$ Endurance exercise training was defined as repetitive, aerobic exercise of large muscles at a constant intensity level for a prolonged period of time (>10 min). ${ }^{14,16}$ Anaerobic exercise training refers to exercise that requires bursts of maximal intensity work over short periods of time $\left(<30\right.$ s). ${ }^{14}$ Strength training was defined as a structured repetitive exercise, inducing an overload to increase strength, power, or muscular endurance. ${ }^{14}$ Mixed training is a combination of interval, endurance, anaerobic, and/or strength training, or a training that does not fit the definition of a specific training type. All studies used different prescribed exercise intensities. Low intensity was defined as $<40 \%$ heart rate reserve, $<64 \%$ peak heart rate or maximal tolerated power, moderate intensity as $40-60 \%$ heart rate reserve, $64-76 \%$ peak heart rate or maximal tolerated power, and high intensity as $>60 \%$ heart rate reserve, $>76 \%$ peak heart rate or maximal tolerated power. ${ }^{16}$ Outcome measures were divided into endurance and sprint wheelchair propulsion capacity. Both are performance measures of wheelchair exercise including all parameters (Figure 1), recording for example power output, speed, or velocity.

Endurance wheelchair propulsion capacity refers to the ability of the body to sustain prolonged wheelchair exercise, and reflects the cardiorespiratory system. ${ }^{17}$ Sprint wheelchair propulsion capacity refers to the ability of the neuromuscular system to produce the greatest possible impulse over a given distance or time period up to 30 seconds. $^{18}$ 
Zwinkels, M., Verschuren, O., Janssen, T.W.J., Ketelaar, M., Takken, T. Exercise training programs to improve hand rim wheelchair propulsion capacity: a systematic review. Clinical Rehabilitation: 2014, 28(9), 847-861

\section{[FIGURE 1]}

\section{Methodological quality}

The methodological quality of the studies was rated using the PEDro scale, based on the Delphi list developed by Verhagen et al., ${ }^{19}$ which consists of eight criteria for internal validity and two statistical criteria. Points were only awarded when a criterion was clearly satisfied and reported.

\section{Evidence level}

The ideal method to determine the efficacy of an intervention is through a randomised controlled trial, a design that ensures that any differences in outcome variables are indeed attributable to the exercise training. To evaluate how to interpret outcome variables of different studies, the levels of evidence were classified by means of a grading system developed by the Oxford Centre of Evidence-Based Medicine. ${ }^{20}$ This classification system consists of five levels. Going from the highest to the lowest level of evidence, these are: 1) randomised controlled trial(s) (n>100), 2) randomised controlled trial, 3) cohort study, 4) clinical controlled trials or case series, and 5) case study.

\section{Results}

Searching the PubMed and EMBASE databases in October 2013 initially resulted in 1158 articles. On the basis of title and abstract, we excluded 1114 studies. Another 23 studies turned out not to meet the inclusion criteria after the full text had been read. Reference screening of the included studies did not result in additional studies. A total of 21 studies were eventually included and divided in different training types (Figure 2). No studies were found on anaerobic training. The studies represented 249 individuals; $50 \%(\mathrm{n}=126)$ diagnosed with spinal cord injury, 38\% $(\mathrm{n}=94)$ were ablebodied participants and $12 \%(n=29)$ were patients diagnosed other than spinal-cord injury. Other diagnoses included spina bifida (4\%), cerebral palsy $(2 \%)$, traumatic injury $(3 \%)$, amputees $(1 \%)$, polio $(1 \%)$, and bilateral tarsal tunnel syndrome $(1 \%)$.

\section{Interval training}

Table 1 lists eight interval training studies, ${ }^{21-28}$ of which three included a control group, ${ }^{26-28}$ though none were randomised controlled trials. Four studies included participants with spinal-cord injury, ${ }^{21,22,24,25}$ and three included healthy ambulatory participants. ${ }^{26-28}$ The number of interval sessions ranged from three to nine sets per training, high-intensity intervals ranged from high intensity to maximal and lowintensity intervals from rest to moderate intensity. All training and test sessions were implemented on a wheelchair ergometer.

All studies measuring endurance wheelchair propulsion capacity found a significant improvement in the experimental group, ranging from 18-34\% in participants with disabilities ${ }^{21-25}$ and $49-66 \%$ in able-bodied participants. ${ }^{26-28}$ No study reported sprint wheelchair propulsion capacity. All studies that measured mechanical efficiency ${ }^{23,23,27}$ or peak oxygen uptake ${ }^{21-23,25,26,28}$ reported significant improvements of $7-15 \%$ and $14-36 \%$, respectively.

\section{Endurance training}

Table 2 lists the results of five studies examining the effects of endurance training. ${ }^{29-}$ ${ }^{33}$ Three studies included a control group, ${ }^{29,32-34}$ one of them being a randomised controlled trial. ${ }^{32}$ Three studies trained experienced wheelchair users, all diagnosed with spinal-cord injury, ${ }^{29-31}$ and four trained men only. ${ }^{30-33}$ Training intensity ranged 
Zwinkels, M., Verschuren, O., Janssen, T.W.J., Ketelaar, M., Takken, T. Exercise training programs to improve hand rim wheelchair propulsion capacity: a systematic review. Clinical Rehabilitation: 2014, 28(9), 847-861

from 30 to $80 \%$ heart rate reserve or 75 to $85 \%$ peak heart rate, and exercise training was executed during arm crank exercise ${ }^{30}$ or wheelchair propulsion on either a wheelchair treadmill, ${ }^{32,33}$ wheelchair ergometer, ${ }^{29}$ or indoor track. ${ }^{31}$ Three studies, of which two trained able-bodied participants, reported a significant positive effect on endurance outcome measures with an improvement of $30-78 \% .^{30,32,33}$ Both studies training able-bodied participants found significant improvements in sprint capacity; 15 and $31 \%$ in 30 -second power output. ${ }^{32,33}$ Significant improvements in peak oxygen uptake of $94 \%$ and $10 \%$ were only found in two studies. ${ }^{30,32}$ Mechanical efficiency was measured in four studies, ${ }^{29,31-33}$ only one of which, with ablebodied participants, found a significant increase of $20 \%{ }^{33}$

\section{Strength training}

Two strength training studies were included (Table 3). ${ }^{35,36}$ No randomised controlled trial was performed.

The studies differed in training duration, frequency, strength exercises and participants: children with cerebral palsy and spina bifida ${ }^{36}$ compared to male adults with and without spinal-cord injury. ${ }^{35}$ A significant improvement was found in endurance capacity during a field test. ${ }^{36}$ Both studies reported sprint wheelchair propulsion capacity, but strength training did not improve sprint performance. However, a significant improvement was found in the strength exercises that were trained. $^{35,36}$

\section{[FIGURE 2]}

\section{Mixed training}

Table 4 lists the characteristics of six mixed training studies. ${ }^{37-42}$ Three studies included a control group, ${ }^{39,41,42}$ one of them being an randomised controlled trial. ${ }^{41}$ Participants had a variety of diagnoses: spinal-cord injury, spina bifida, trauma, polio, and cerebral palsy. With one exception, ${ }^{38}$ all studies trained experienced wheelchair users or even wheelchair athletes. ${ }^{41,42}$ Three exercise programs consisted of a combination of strength and endurance training, ${ }^{37-39}$ one study used wheelchair exercise to exhaustion, ${ }^{40}$ and two studies investigated respiratory muscle training. ${ }^{41,42}$ Exercise training programs lasted between six weeks and 10 months and involved one to 14 training sessions each week.

Endurance wheelchair propulsion capacity improved significantly, by $30-53 \%$ in terms of endurance time ${ }^{39,40}$ and by $15 \%$ in terms of maximal tolerated power. ${ }^{37} \mathrm{~A}$ case study reported an increase of $63 \%$ in $10-\mathrm{km}$ time trial. ${ }^{38}$ One study reported a significant improvement in sub-maximal endurance time, but found no increase in maximal tolerated power. ${ }^{39}$ No difference was found in sprint capacity. ${ }^{42}$

\section{Methodological quality}

Tables 1-4 report the methodological quality as assessed with the PEDro scale. The median score was two out of 10, and no study scored more than six points, indicating generally poor methodological quality. Only two out of 21 studies were randomised controlled trials, ${ }^{32,41}$ but these studies could not ensure concealed allocation and blinding of subjects, therapists or assessors. Most studies had positive scores on criteria eight and 11 , indicating that more than $85 \%$ of the subjects completed the intervention and the effect of treatment was measured. 
Zwinkels, M., Verschuren, O., Janssen, T.W.J., Ketelaar, M., Takken, T. Exercise training programs to improve hand rim wheelchair propulsion capacity: a systematic review. Clinical Rehabilitation: 2014, 28(9), 847-861

\section{Evidence level}

Two out of 21 studies obtained their results at the second highest level of evidence that of small sample size randomised controlled trial. ${ }^{32,41}$ Another five studies were controlled clinical trials. ${ }^{26-28,33,42}$ The majority of studies $(57 \%, n=12)$ consisted of observational studies comparing post-training results with baseline values, and two articles reported on case studies.

\section{[TABLE 1]}

\section{[TABLE 2]}

\section{[TABLE 3]}

\section{[TABLE 4]}

\section{DISCUSSION}

Although the evidence base is weak, the present review does support exercise training programs as being beneficial for improving wheelchair propulsion capacity. The vast majority of participants involved had a spinal-cord injury or were ablebodied individuals. It is surprising that there were only two proper randomised controlled trials. ${ }^{32,41}$ Furthermore, only five out of 21 studies reported between-group differences. ${ }^{26,32,33,41,42}$ The majority of studies were case series or even case studies, indicating changes over time that can be due to any factor, such as exposure to the test protocol, natural recovery, season or learning effects. ${ }^{43}$ Studies without betweengroup differences do not provide sufficient evidence for the effectiveness of exercise training.

Arm cranking, an outcome measure used in many studies, requires a continuous pushing and pulling movement instead of the intermittent propelling pattern of wheelchair propulsion. Moreover, arm cranking exercise has a higher peak power output and mechanical efficiency. ${ }^{44,45}$ Considering the concept of specificity of exercise, wheelchair propulsion exercise is more appropriate. It improves the capability in using a manual wheelchair, as shown in this review by improvements in mechanical efficiency. The focus in the current review was specifically on wheelchair propulsion, being the primary means of mobility in wheelchair users. So, studies that used arm cranking as an outcome measure were not included. Twenty studies included in the review by Valent et al. ${ }^{13}$ were therefore not included in the current review. The other focus of the current review, including not only individuals with spinal-cord injury, resulted in $12 \%$ of participants involved having a other diagnosis and $38 \%$ able-bodied participants. This does not represent the wheelchair using population, and therefore more research is needed.

The intervention programs in the included studies varied in terms of duration, frequency, and intensity. The American College of Sports Medicine (ACSM) guidelines for wheelchair users with paraplegia recommend 3-5 exercise sessions a week lasting 20-60 minutes each, at moderate to vigorous exercise intensities, to increase aerobic capacity ${ }^{46}$, the most important physiological parameter. This suggests target heart rates between 50 and $80 \%$ of peak heart rate. ${ }^{46}$ Therefore, strength training programs fall out of the scope in this comparison. 
Zwinkels, M., Verschuren, O., Janssen, T.W.J., Ketelaar, M., Takken, T. Exercise training programs to improve hand rim wheelchair propulsion capacity: a systematic review. Clinical Rehabilitation: 2014, 28(9), 847-861

Except for both respiratory muscle training programs, ${ }^{41,42}$ all interventions met the ACSM guidelines for increasing aerobic capacity. The ACSM guidelines for wheelchair users only account for the physical fitness parameters.

Therefore it seems reasonable to assume that respiratory muscle training was not effective in improving wheelchair propulsion capacity, since physiological parameters or mechanical efficiency during wheelchair propulsion were not trained. Inclusion of all types and modes of training programs as well as all diagnoses provided a nice overview, but did not result in potential training guidelines. However, despite our finding that no randomised controlled trial had been performed for interval training, this type of training seems to have the highest potential to improve endurance wheelchair propulsion capacity. All participants in seven intervention studies improved significantly in terms of endurance capacity and peak oxygen uptake, whereas the participants in endurance and mixed training programs showed both endurance capacity and peak oxygen uptake improvement only in two out of five and one out of five studies, respectively. This cautious conclusion supports the findings of Helgerud et al. ${ }^{47}$ and Gibala et al. ${ }^{48}$ who found that highintensity interval training is significantly more effective in improving peak oxygen uptake than performing the same (or more) total work during continuous aerobic exercise training. However, more research is needed to find out whether this also holds for wheelchair exercise.

Assuming that exercise intensity is the most important factor in improving aerobic capacity in healthy subjects, rather than exercise frequency and duration, ${ }^{17}$ it is remarkable that studies training at moderate ${ }^{29}$ or high $^{29,31}$ intensity found no significant improvements, while a study training at low intensity ${ }^{33}$ did. The positive training effect was found in able-bodied participants. Despite that this group had similar peak power outputs compared to individuals with paraplegia, this suggest that training effects are achieved at lower intensities in ablebodied individuals. ${ }^{49}$ Ablebodied participants gained the most effect at the start of the intervention in improving mechanical efficiency. ${ }^{50}$ In contrast, despite of the similar training guidelines, ${ }^{16}$ and baseline measurements ${ }^{49}$ the effect of interval and endurance training in individuals with disabilities was lower compared to able-bodied participants.

The limiting factor for improving peak oxygen uptake in individuals with a disability is generally a lack of active muscle mass. ${ }^{51}$ Resistance training or electrical induced resistance training can increase muscle mass ${ }^{52,53}$ and might have a positive effect on peak oxygen uptake.

Only six out of 21 studies investigated sprint wheelchair propulsion capacity. Significant improvements in sprint capacity in able-bodied participants may again represent an overestimation of the effects in experienced wheelchair users. ${ }^{32,33}$ The improved strength in single- and multiple-joint exercises after strength training was not translated into an improvement in sprint capacity. ${ }^{35,36}$ Although there is a correlation between muscle strength and the force imparted to the hand rim, increased force does not necessarily lead to more effective hand rim force or propulsion cadence. ${ }^{54}$ This suggests that improving not only muscle strength, but also propulsion technique is important. Future research should use exercise programs incorporating both muscle strength exercises specifically designed to improve handrim propulsion and functional, effective propulsion technique training. In wheelchair users with a spinal-cord injury, aerobic capacity accounts for $69 \%$ of maximal tolerated power during wheelchair propulsion. ${ }^{55}$ This makes peak oxygen 
Zwinkels, M., Verschuren, O., Janssen, T.W.J., Ketelaar, M., Takken, T. Exercise training programs to improve hand rim wheelchair propulsion capacity: a systematic review. Clinical Rehabilitation: 2014, 28(9), 847-861

uptake an important physical fitness parameter. All studies in which peak oxygen uptake improved significantly also found improved endurance capacity. The same pattern holds for mechanical efficiency; when mechanical efficiency improved significantly, endurance capacity improved as well.

A highly significant relation between mechanical efficiency and maximal tolerated power supports this finding. ${ }^{56}$ Both peak oxygen uptake and mechanical efficiency are good predictive physical fitness parameters for wheelchair propulsion capacity. In the study by DiCarlo et al. ${ }^{30}$ peak oxygen uptake values improved by no less than $94.2 \%$, from 12.1 to $23.5 \mathrm{~mL} \mathrm{O}^{2} / \mathrm{kg} / \mathrm{min}$. Baseline measurements indicated very low aerobic capacities, and the very large effect may be explained by the relative notation of peak oxygen uptake in combination with increased muscle mass and weight loss. Our findings must be interpreted in light of certain limitations. First, the search might have missed some studies. We have looked at outcome measures specifically performed during hand rim wheelchair propulsion and therefore training studies with outcome measures on endurance or sprint capacity during hand cycling have been missed.

Second, there have been no studies on this topic with a high level of evidence and with good methodological quality. Without between-group analyses, changes over time can be due to any factor. ${ }^{43}$ Moreover, in view of the low levels of evidence, low methodological quality and heterogeneity of both study sample and interventions, it was inappropriate to pool the data of the studies included.

Third, a plethora of different not equally divided diagnoses makes it difficult to interpret the results.

Several studies were even conducted among healthy ambulatory subjects. Hence, further investigations are required to assess whether our results are generalizable to other diagnoses and medical conditions. Fourth, the studies in our review predominantly included male participants. It is unclear whether the same effects would be observed in women. Fifth, not all training types were equally represented. We could only include two studies on strength training, and no studies investigating the effects of anaerobic training.

This is surprising, since for manual wheelchair users, most of the motor activities in daily life are of short duration ${ }^{10}$ and produce a relatively high physical strain on the individual. Finally, there was only one training study that focused on children using a wheelchair. Although long-term effects of training are not known, one can only assume that an early introduction to wheelchair training would be beneficial for children's future health and function.

There is a need for randomised controlled trials involving manual wheelchair users, particularly including people who do not have spinal-cord injury. Future research should also focus on the effects of interval training, since, based on the lowquality evidence, this seems to be the training type that has the greatest potential. In addition, there is a need for studies investigating the effects of exercise training in children using a wheelchair.

\section{Acknowledgements}

We are grateful to Paulien Wiersma for her contribution to the literature search and to Svenja Leferink for checking table information with corresponding articles.

\section{Conflict of interest}

None declared.

\section{Funding}


Zwinkels, M., Verschuren, O., Janssen, T.W.J., Ketelaar, M., Takken, T. Exercise training programs to improve hand rim wheelchair propulsion capacity: a systematic review. Clinical Rehabilitation: 2014, 28(9), 847-861

This work was supported by the Phelps Foundation (2012004) and ZonMw (525001005).

\section{Notes}

Sport-2-Stay-Fit study group: FJG Backx (Department of Rehabilitation, Nursing Science and Sports, and Brain Center Rudolf Magnus, University Medical Center Utrecht, Utrecht, The Netherlands), JF de Groot (University of Applied Sciences, Utrecht, The Netherlands), T Takken (Child Development and Exercise Center, University Medical Center Utrecht, Utrecht, The Netherlands), DW Smits (Department of Rehabilitation, Nursing Science and Sports, and Brain Center Rudolf Magnus, University Medical Center Utrecht, Utrecht, The Netherlands), OW Verschuren (Brain Center Rudolf Magnus, University Medical Center Utrecht, and De Hoogstraat Rehabilitation, Utrecht, The Netherlands), JMA Visser-Meily (Department of Rehabilitation, Nursing Science and Sports, and Brain Center Rudolf Magnus, University Medical Center Utrecht, and De Hoogstraat Rehabilitation, Utrecht, The Netherlands), MJ Volman (Faculty of Social Sciences, Department of General and Special Education, Utrecht University, Utrecht, The Netherlands), HW Wittink (University of Applied Sciences, Utrecht, The Netherlands), and M Zwinkels (Brain Center Rudolf Magnus, University Medical Center Utrecht, and De Hoogstraat Rehabilitation, Utrecht, The Netherlands)

\section{REFERENCES}

1. Nooijen CF, de Groot S, Postma K, Bergen MP, Stam HJ, Bussmann JB, et al. A more active lifestyle in persons with a recent spinal cord injury benefits physical fitness and health. Spinal Cord 2012; 50: 320-323.

2. Tolerico ML, Ding D, Cooper RA, Spaeth DM, Fitzgerald SG, Cooper R, et al. Assessing mobility characteristics and activity levels of manual wheelchair users. J Rehabil

Res Dev 2007; 44: 561-571.

3. Warms CA, Whitney JD and Belza B. Measurement and description of physical activity in adult manual wheelchair users. Disabil Health J 2008; 1: 236-244.

4. Haisma JA, van der Woude LH, Stam HJ, Bergen MP, Sluis TA and Bussmann JB. Physical capacity in wheelchair- dependent persons with a spinal cord injury: a critical review of the literature. Spinal Cord 2006; 44: 642-652.

5. Ravenek KE, Ravenek MJ, Hitzig SL and Wolfe DL.

Assessing quality of life in relation to physical activity participation in persons with spinal cord injury: A systematic review. Disabil Health J 2012; 5: 213-223.

6. Manns PJ and Chad KE. Components of quality of life for persons with a quadriplegic and paraplegic spinal cord injury. Qual Health Res 2001; 11: 795-811.

7. Lundqvist C, Siosteen A, Blomstrand C, Lind B and Sullivan M. Spinal cord injuries. Clinical, functional, and emotional status. Spine (Phila Pa 1976) 1991; 16: 78-83.

8. Janssen TW, van Oers CA, van der Woude LH and Hollander AP. Physical strain in daily life of wheelchair users with spinal cord injuries. Med Sci Sports Exerc 1994; 26: 661-670.

9. Caspersen CJ, Powell KE and Christenson GM. Physical activity, exercise, and physical fitness: definitions and distinctions for health-related research. Public Health Rep 1985; 100: 126-131.

10. Sonenblum SE, Sprigle S and amd Lopez RA. Manual wheelchair use: bouts of mobility in everyday life. Rehabil

Res Pract 2012; 753165.

11. Van der Woude $L$, de Groot $S$, Van Drongelen $S$, Janssen $T$, Haisma J, Valent $L$ and Veeger D. Evaluation of manual wheelchair performance in everyday life. Top Spinal Cord Inj Rehabil 2009; 15: 1-15. 
Zwinkels, M., Verschuren, O., Janssen, T.W.J., Ketelaar, M., Takken, T. Exercise training programs to improve hand rim wheelchair propulsion capacity: a systematic review. Clinical

Rehabilitation: 2014, 28(9), 847-861

12. Dallmeijer AJ, Kilkens OJ, Post MW, de Groot S, Angenot EL, van Asbeck FW, et al. Hand-rim wheelchair propulsion capacity during rehabilitation of persons with spinal cord injury. J Rehabil Res Dev 2005; 42(3 Suppl 1): 55-63.

13. Valent L, Dallmeijer A, Houdijk H, Talsma $E$ and van der Woude L. The effects of upper body exercise on the physical capacity of people with a spinal cord injury: a systematic review. Clin Rehabil 2007; 21: 315-330.

14. US Department of Health and Human Services. Physical activity and health: a report of the Surgeon General. Jones \& Bartlett Learning, 1996.

15. Waehner P. Interval Training. 2011. Available at: http:// exercise.about.com/cs/cardioworkouts/g/intervaltrainin. htm (accessed September 2013).

16. American College of Sports Medicine. General Principles

of Exercise Prescription. ACSM's Guidelines for Exercise

Testing and Prescription. 8th ed. Philadelphia: Lippincott Williams \& Wilkins, 2009, p. 152.

17. Wilmore $\mathrm{JH}$ and Costill DL. Physiology of Sport and

Exercise. 3rd ed. Hong Kong: Human Kinetics, 2004, pp.

206-241.

18. Van Praagh ED. Short-term muscle power during growth and maturation. Sports medicine 2002; 32: 701-728.

19. Verhagen AP, de Vet HC, de Bie RA, Kessels AG, Boers M, Bouter LM, et al. The Delphi list: a criteria list for quality assessment of randomized clinical trials for conducting systematic reviews developed by Delphi consensus.

$\mathrm{J}$ Clin Epidemiol 1998; 51: 1235-1241.

20. OCEBM Levels of Evidence Working Group. The Oxford 2011 Levels of Evidence. 2011. Available at: http://www.

cebm.net/index.aspx?o=5653 (accessed September 2013), 1998.

21. Bougenot MP, Tordi N, Betik AC, Martin X, Le Foll D, Parratte B, et al. Effects of a wheelchair ergometer training programme on spinal cord-injured persons. Spinal Cord 2003; 41: 451-456.

22. Tordi N, Dugue B, Klupzinski D, Rasseneur L, Rouillon JD and Lonsdorfer J. Interval training program on a wheelchair ergometer for paraplegic subjects. Spinal Cord 2001; 39: 532-537.

23. Miles DS, Sawka MN, Wilde SW, Durbin RJ, Gotshall RW and Glaser RM. Pulmonary function changes in wheelchair athletes subsequent to exercise training.

Ergonomics 1982; 25: 239-246.

24. Yim SY, Cho KJ, Park CI, Yoon TS, Han DY, Kim SK, et al. Effect of wheelchair ergometer training on spinal cord-injured paraplegics. Yonsei Med J 1993; 34: 278-286.

25. Le Foll-de Moro D, Tordi N, Lonsdorfer E and Lonsdorfer J. Ventilation efficiency and pulmonary function after a wheelchair interval-training program in subjects with recent spinal cord injury. Arch Phys Med Rehabil 2005; 86: 1582-1586.

26. Tordi N, Gimenez M, Predine E and Rouillon JD. Effects of an interval training programme of the upper limbs on a wheelchair ergometer in able-bodied subjects. Int $\mathrm{J}$ Sports

Med 1998 ;19: 408-414.

27. Glaser RM, Sawka MN, Durbin RJ, Foley DM and Suryaprasad AG. Exercise program for wheelchair activity.

Am J Phys Med 1981; 60: 67-75.

28. Tordi N, Belli A, Mougin F, Rouillon JD and Gimenez M.

Specific and transfer effects induced by arm or leg training.

Int J Sports Med 2001; 22: 517-524.

29. Hooker SP and Wells CL. Effects of low- and moderateintensity training in spinal cordinjured persons. Med Sci

Sports Exerc 1989; 21: 18-22.

30. DiCarlo SE. Effect of arm ergometry training on wheelchair propulsion endurance of individuals with quadriplegia.

Phys Ther 1988; 68: 40-44.

31. Whiting RB, Dreisinger TE, Dalton RB and Londeree BR. 
Zwinkels, M., Verschuren, O., Janssen, T.W.J., Ketelaar, M., Takken, T. Exercise training programs to improve hand rim wheelchair propulsion capacity: a systematic review. Clinical Rehabilitation: 2014, 28(9), 847-861

Improved physical fitness and work capacity in quadriplegics by wheelchair exercise. J Card Rehabil 1983; 3: 251-255.

32. van der Woude LH, van Croonenborg JJ, Wolff I, Dallmeijer AJ and Hollander AP. Physical work capacity after 7 wk of wheelchair training: effect of intensity in able-bodied subjects. Med Sci Sports Exerc 1999; 31: 331-341.

33. Van den Berg R, de Groot S, Swart KM and van der Woude LH. Physical capacity after 7 weeks of lowintensity wheelchair training. Disabil Rehabil 2010; 32: 2244-2252.

34. Van den Berg-Emons RJ, Van Baak MA, Speth L and Saris WH. Physical training of school children with spastic cerebral palsy: effects on daily activity, fat mass and fitness. Int J Rehabil Res 1998; 21: 179-194.

35. Turbanski $S$ and Schmidtbleicher $D$. Effects of heavy resistance training on strength and power in upper extremities in wheelchair athletes. J Strength Cond Res 2010; 24: 8-16.

36. O'Connell DG and Barnhart R. Improvement in wheelchair propulsion in pediatric wheelchair users through resistance training: a pilot study. Arch Phys Med Rehabil 1995; 76: 368-372.

37. Rodgers MM, Keyser RE, Rasch EK, Gorman PH and Russell PJ. Influence of training on biomechanics of wheelchair propulsion. J Rehabil Res Dev 2001; 38: 505-511.

38. Lakomy HK and Williams T. The responses of an able bodied person to wheelchair training: a case study. $\mathrm{Br} \mathrm{J}$

Sports Med 1996; 30: 236-237.

39. Keyser RE, Rasch EK, Finley M and Rodgers MM.

Improved upper-body endurance following a 12-week home exercise program for manual wheelchair users. J

Rehabil Res Dev 2003; 40: 501-510.

40. Gass GC, Watson J, Camp EM, Court HJ, McPherson LM and Redhead P. The effects of physical training on high level spinal lesion patients. Scand J Rehabil Med 1980; 12: 6165.

41. Mueller G, Perret C and Hopman MT. Effects of respiratory muscle endurance training on wheelchair racing performance in athletes with paraplegia: a pilot study. Clin $\mathrm{J}$

Sport Med 2008 ;18: 85-88.

42. Goosey-Tolfrey VF, Foden EF, Perret CF and Degens H. Effects of inspiratory muscle training on respiratory function and repetitive sprint performance in wheelchair basketball players. British journal of sports medicine JID

- 04325200701.

43. Herbert R, Jamtvedt G, Mead J and Hagen K. Pratical

Evidence-Based Physiotherapy. Oxford: Elsevier, 2005, pp. 25-27.

44. Hintzy F Tordi and N Perrey S. Muscular efficiency during arm cranking and wheelchair exercise: a comparison.

Int J Sports Med 2002; 23: 408-414.

45. Martel G Noreau and L Jobin J. Physiological responses to maximal exercise on arm cranking and wheelchair ergometer with paraplegics. Paraplegia 1991; 29: 447-456.

46. Durstine JL, Moore GE, Painter PL and Roberts SO.

Spinal Cord Disabilities: Paraplegia and Tetraplegia. In: Figoni S (ed). ACSM's exercise management for persons

with chronic diseases and disabilities. JL: Human Kinetics Champaign, 2009, pp. 298-305.

47. Helgerud J, Hoydal K, Wang E, Karlsen T, Berg P, Bjerkaas M, et al. Aerobic highintensity intervals improve VO2max more than moderate training. Med Sci

Sports Exerc 2007; 39: 665-671.

48. Gibala M, Little J, Macdonald M and Hawley J.

Physiological adaptations to low-volume, high-intensity interval training in health and disease. J Physiol (Lond)

2012; 590: 1077-1084.

49. Keyser RE, Rodgers MM, Gardner ER and Russell PJ. Oxygen uptake during peak graded exercise and single-stage fatigue tests of wheelchair propulsion in manual wheelchair users and the able-bodied. Arch

Phys Med Rehabil 1999; 80: 1288-1292.

50. Van der Woude LH, de Groot G, Hollander AP, van Ingen Schenau GJ and Rozendal

$\mathrm{RH}$. Wheelchair ergonomics and physiological testing of prototypes. Ergonomics 
Zwinkels, M., Verschuren, O., Janssen, T.W.J., Ketelaar, M., Takken, T. Exercise training programs to improve hand rim wheelchair propulsion capacity: a systematic review. Clinical Rehabilitation: 2014, 28(9), 847-861

1986; 29: 1561-1573.

51. Vinet A, Le Gallais D, Bernard PL, Poulain M, Varray A, Mercier J, et al. Aerobic metabolism and cardioventilatory responses in paraplegic athletes during an incremental wheelchair exercise. Eur J Appl Physiol Occup Physiol

1997; 76: 455-461.

52. Serra-Añó P, Pellicer-Chenoll M, García-Massó X, Morales J, Giner-Pcual M and González LM. Effects of resistance training on strength, pain and shoulder functionality in paraplegics. Spinal Cord 2012; 50: 827-831.

53. Ryan T, Brizendine J, Backus D and McCully K.

Electrically induced resistance training in individuals with motor complete spinal cord injury. Arch Phys Med

Rehabil 2013; 94: 2166-2173.

54. Ambrosio F, Boninger ML, Souza AL, Fitzgerald SG, Koontz AM and Cooper RA. Biomechanics and strength of manual wheelchair users. J Spinal Cord Med 2005; 28: 407414.

55. Kilkens OJ, Dallmeijer AJ, Nene AV, Post MW and van der Woude LH. The longitudinal relation between physical capacity and wheelchair skill performance during inpatient rehabilitation of people with spinal cord injury.

Arch Phys Med Rehabil 2005; 86: 1575-1581.

56. Tropp H, Samuelsson K and Jorfeldt L. Power output for wheelchair driving on a treadmill compared with arm crank ergometry. Br J Sports Med 1997; 31: 41-44.

57. Medbo JI, Mohn AC, Tabata I, Bahr R, Vaage O and Sejersted OM. Anaerobic capacity determined by maximal accumulated O2 deficit. J Appl Physiol 1988; 64: 50-60. 
Zwinkels, M., Verschuren, O., Janssen, T.W.J., Ketelaar, M., Takken, T. Exercise training programs to improve hand rim wheelchair propulsion capacity: a systematic review. Clinical Rehabilitation: 2014, 28(9), 847-861

\section{TABLES AND FIGURES}

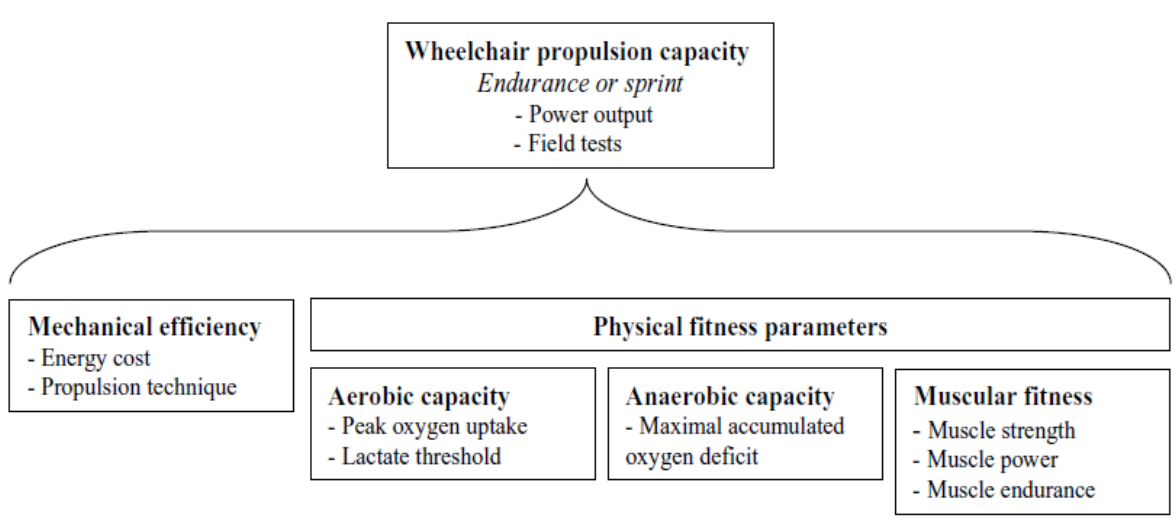

Figure I. Schematic relationship of wheelchair propulsion capacity and underlying parameters. ${ }^{17,57}$

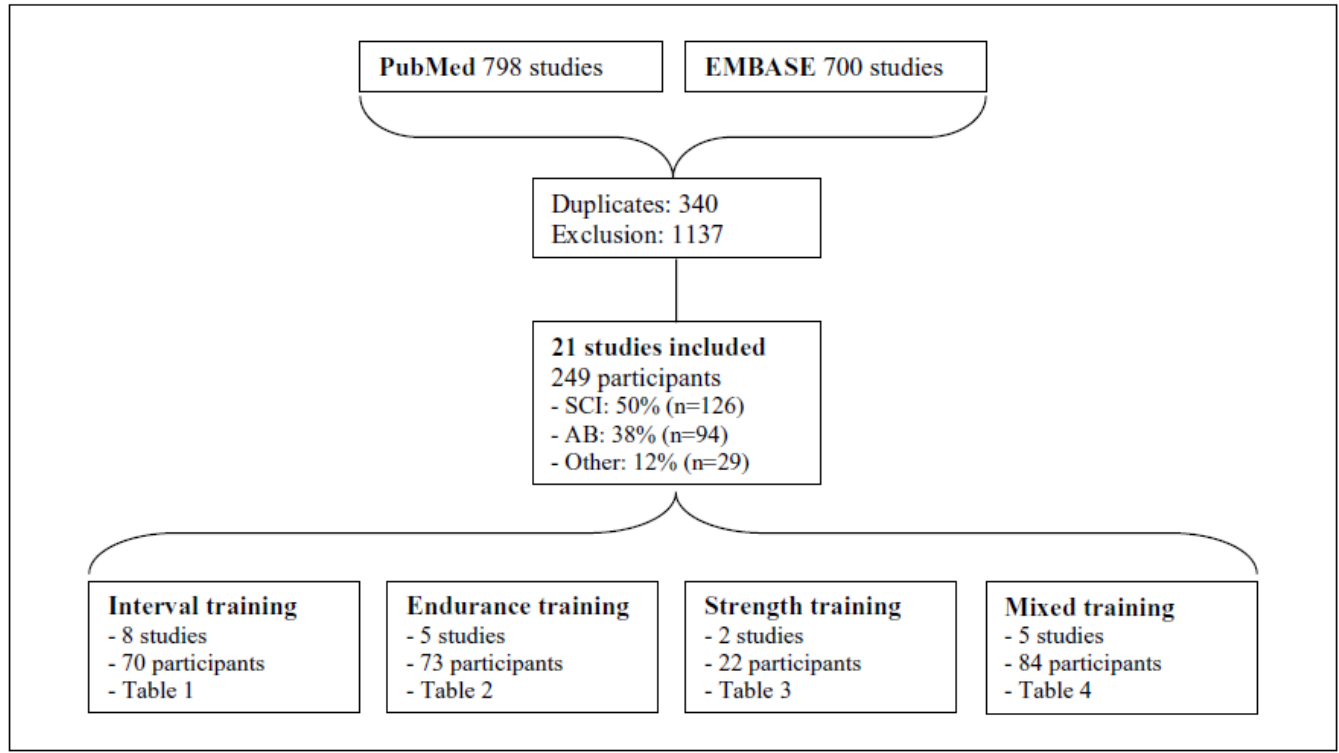

Figure 2. Flowchart for selection of eligible articles.

$\mathrm{SCl}$, spinal-cord injury, AB, able-bodied, other, participants having other diseases than spinal-cord injury. 
Zwinkels, M., Verschuren, O., Janssen, T.W.J., Ketelaar, M., Takken, T. Exercise training programs to improve hand rim wheelchair propulsion capacity: a systematic review. Clinical

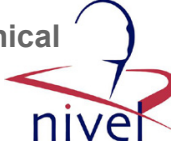

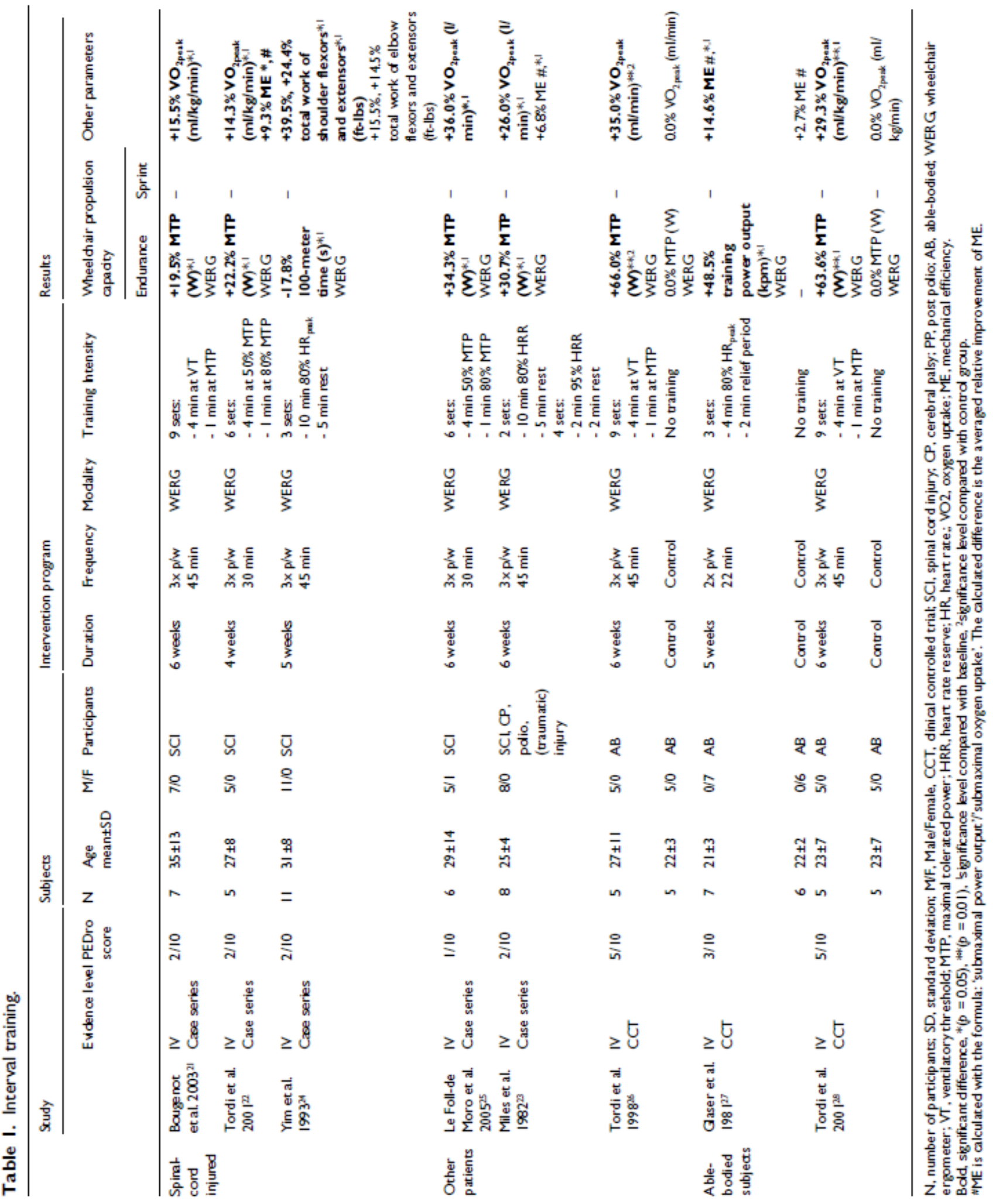


Zwinkels, M., Verschuren, O., Janssen, T.W.J., Ketelaar, M., Takken, T. Exercise training programs to improve hand rim wheelchair propulsion capacity: a systematic review. Clinica

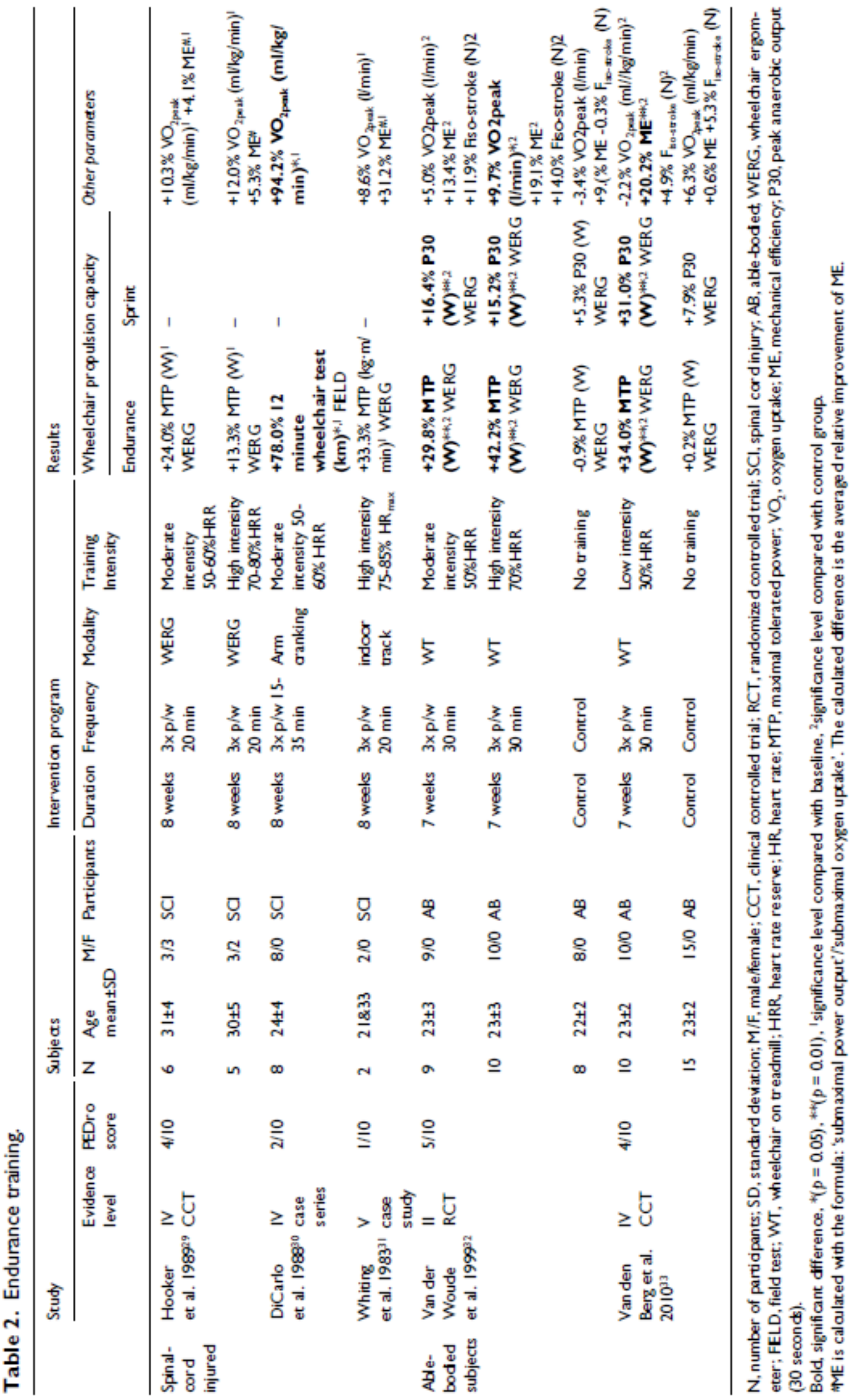


Zwinkels, M., Verschuren, O., Janssen, T.W.J., Ketelaar, M., Takken, T. Exercise training programs to improve hand rim wheelchair propulsion capacity: a systematic review. Clinica

Rehabilitation: 2014, 28(9), 847-861

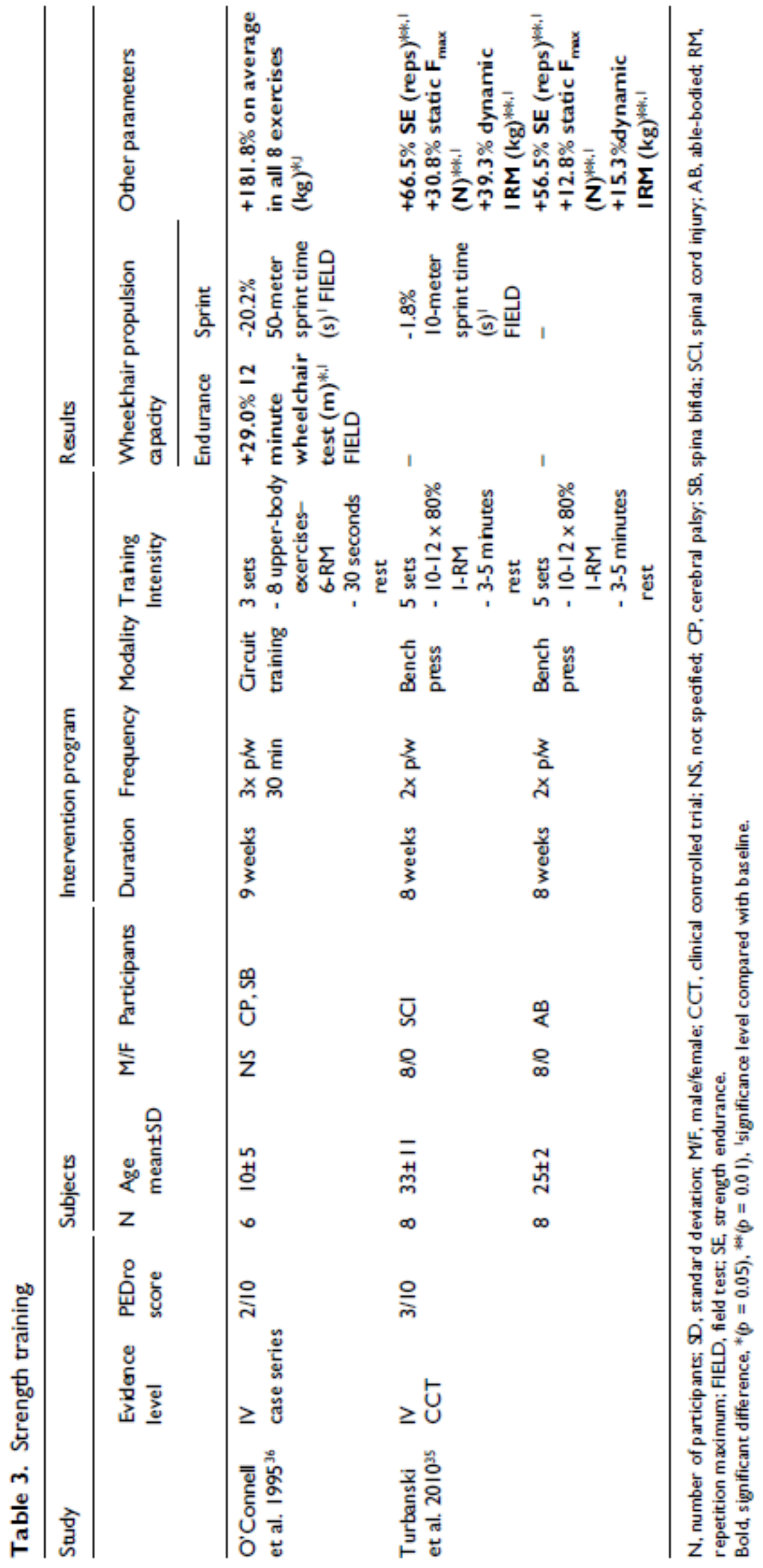


Zwinkels, M., Verschuren, O., Janssen, T.W.J., Ketelaar, M., Takken, T. Exercise training programs to improve hand rim wheelchair propulsion capacity: a systematic review. Clinical Rehabilitation: 2014, 28(9), 847-861
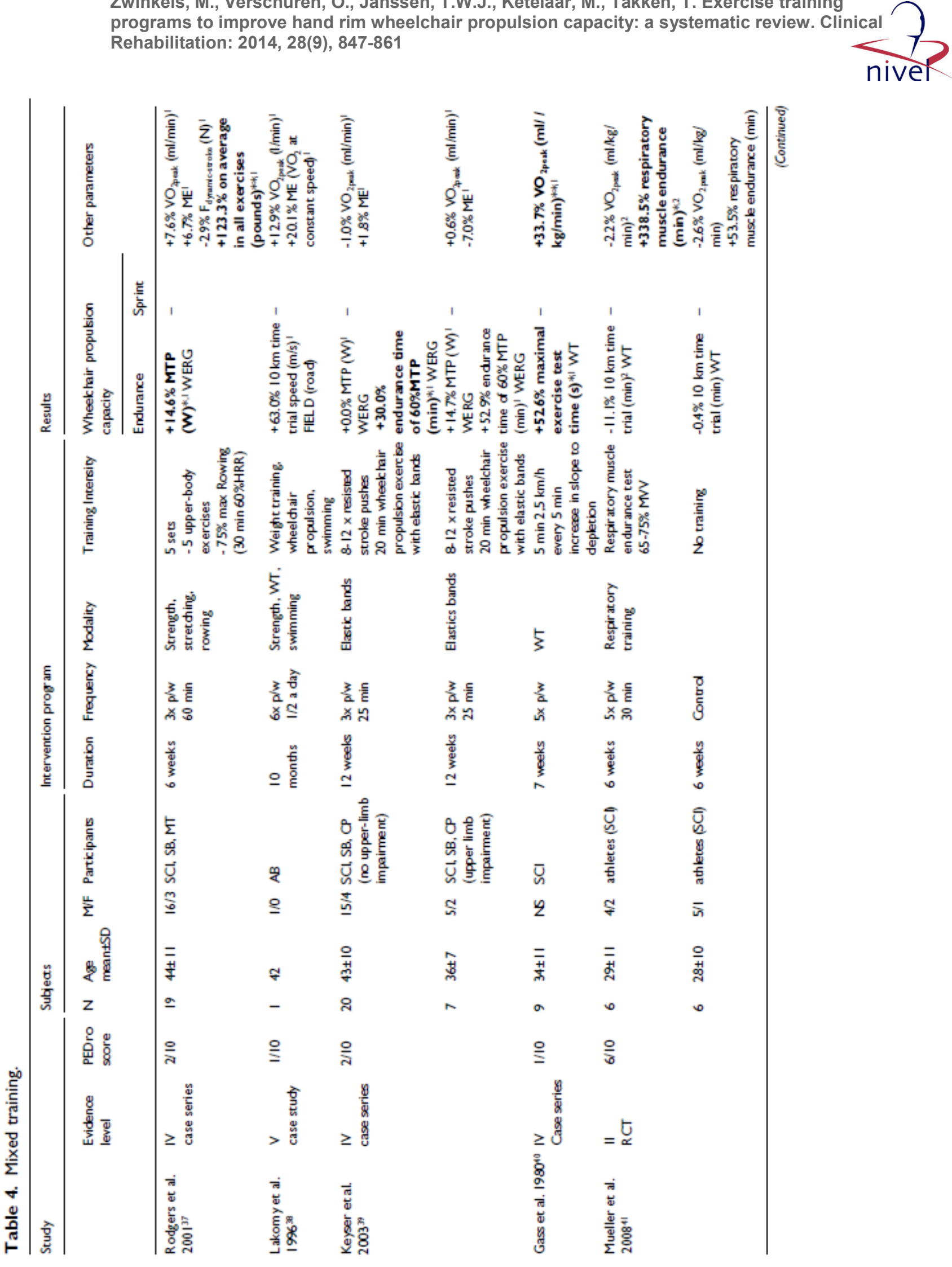
Zwinkels, M., Verschuren, O., Janssen, T.W.J., Ketelaar, M., Takken, T. Exercise training programs to improve hand rim wheelchair propulsion capacity: a systematic review. Clinical

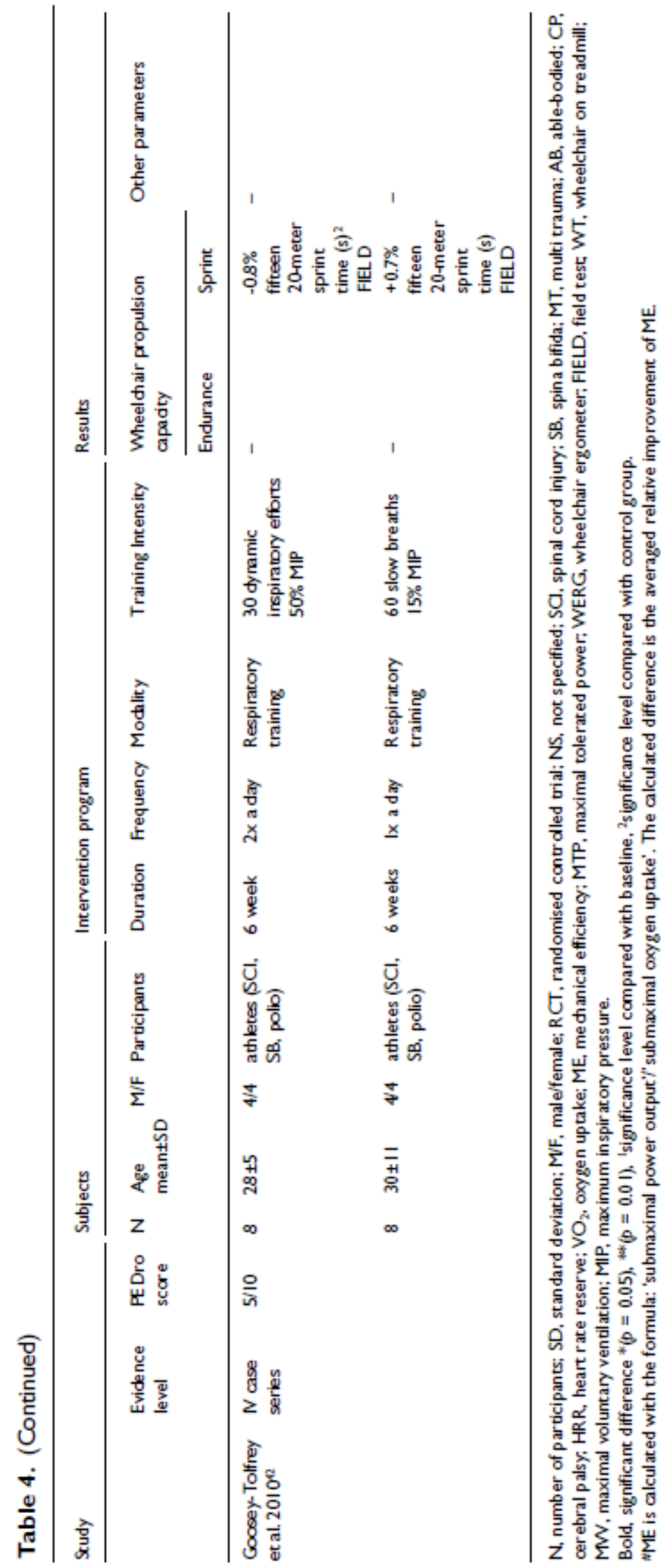

